\title{
Influence of Homogenization on Mechanical Properties of Al-1Mn-1Mg Alloy Prepared by Different Melt-Treatments
}

\author{
Yonglu Chen ${ }^{*},{ }^{1}$ Lihua Hong ${ }^{1}$, Liangdeng Wang ${ }^{2}$ and Wenzhe Chen ${ }^{1}$ \\ ${ }^{I}$ School of Material Science and Engineering, Fujian University of Technology, Fuzhou, 350108, China \\ ${ }^{2}$ School of Machine Engineering and Automation, Fuzhou University, Fuzhou, 350108, China
}

\begin{abstract}
Influence of homogenization on mechanical properties of Al-1Mn-1Mg alloy prepared by different melttreatments was discussed and mechanism of metallurgical defects on ingots' mechanical properties was analyzed. It was found that metallurgical defects, such as the inclusions and gas holes, cannot be removed from the original ingots by homogenization; the average increasement of tensile strength of the ingots prepared by comprehensive melt-treatment and homogenized at $400 \sim 500^{\circ} \mathrm{C}$ for 12 hours was $17.4 \%$, and the elongation improved slightly; the better obdurability of the ingots can be obtained due to the vast reduction of crack initiation of metallurgical defects such as the inclusions, gas holes and so on; the fracture mode gave priority to the type of transcrystalline and micropore gathering; under the experiment condition, the relatively optimized processing permanents of homogenization can be obtained by heating at $450 \sim 500^{\circ} \mathrm{C}$ while holding for 12 hours and air cooling; the comprehensive mechanical properties of the ingots, prepared by the optimized process, can be tested as follows: $\sigma_{\mathrm{b}} \approx 180 \sim 193 \mathrm{MPa}, \delta \approx 16.0 \sim 18.0 \%$.
\end{abstract}

Keywords: Homogenization, melt-treatment, Al-1Mn-1Mg alloy, mechanical properties, metallurgical defects.

\section{INTRODUCTION}

Al-1Mn-1Mg alloy sheet used for can was the typical representative of high precision and special thin aluminum sheets, and the symbol of modern processing level of aluminum in one country. Crystal segregation and regional segregation often appeared in the ingots during the casting, owing to the rapid cooling and non-equilibrium crystallization, and the non-equilibrium eutectic phase formed, i.e. non-equilibrium excess phase. In order to overcome the influence of non-equilibrium excess phases in the grain boundary on rolling process and the following drawing and bulging for cans, the existing research and production practice always paid more attention to the homogenization [1-4], that is, the high temperature and long time heat-treatment can promote the dissolving of non- the rolling and the cans' quality, were not only the nonequilibrium excess phases that can be dissolved by hightemperature heat-treatment, but also the insoluble coarse particles, such as $\mathrm{Al}_{2} \mathrm{O}_{3}$ and other inclusions. They were the critical factors influencing the cans' quality, and should be treated differently. Therefore, the effect of the liquid alloy processing (melt-treatment) and that of the solid alloy processing (homogenization) on the mechanical properties, and the interaction mechanism of the two processes, were studied in this paper, to provide the test basis of improving the preparation techniques of $\mathrm{Al}-1 \mathrm{Mn}-1 \mathrm{Mg}$ alloy ingots.

\section{MATERIAL AND EXPERIMENTATION}

The main ingredient of $\mathrm{Al}-1 \mathrm{Mn}-1 \mathrm{Mg}$ alloy prepared in this research is shown in Table $\mathbf{1}$.

Table 1. Ingredient of Al-1Mn-1Mg Alloy (wt\%)

\begin{tabular}{|c|c|c|c|c|c|c|c|}
\hline Element & Mn & Mg & Fe & Si & Cu & Ti & Al \\
\hline \hline Content & $0.7 \sim 1.2$ & $0.8 \sim 1.3$ & $0.4 \sim 0.5$ & $0.2 \sim 0.25$ & $0.15 \sim 0.25$ & $0.03 \sim 0.05$ & Bal. \\
\hline
\end{tabular}

equilibrium excess phase, improve the diffusion ability of atoms in favor of accelerating the conversion process from the non-equilibrium to the equilibrium, thereby the homogenous matrix can be obtained. However, the impurity in the aluminum ingot that had direct or indirect effects on

*Address correspondence to this author at the School of Material Science and Engineering, Fujian University of Technology, Fuzhou, 350108, China; Tel: 86-591-22863279; Fax: 86-591-22863279;

E-mail: chenyl_76@126.com
Two kinds of melt-treatment technologies have been adopted individually in the smelting. The first technology was the routine production of aluminum ingots. The commercial flux for melt refining and the domestic Al-5Ti1B intermediate alloy (rod shape) for grain refining were adopted in the first technology, which was referred to as process A. The second one was designed specially for melttreatment of Al-1Mn-1Mg alloy, in which the self-developed high-efficient active flux for removing inclusions and the self-made metamorphic additive named M3 were added [5]. 


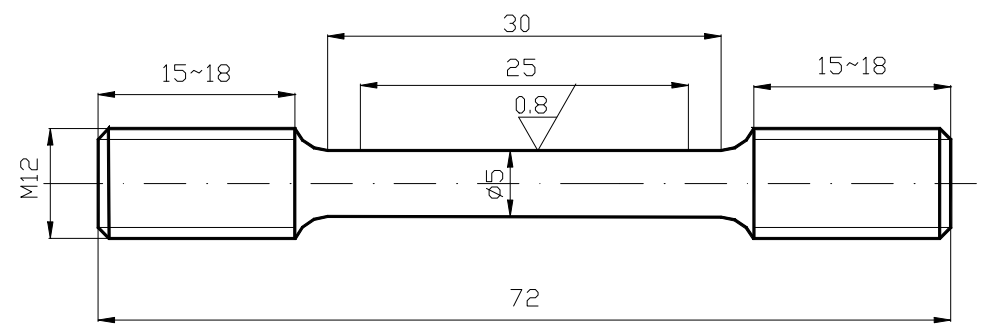

Fig. (1). Design chart of the tensile sample.

The process of removing inclusions was the method of flux filtration purification [6], and the processes of degassing refining and grain refining were the same to process $\mathrm{A}$. The second technology was referred to as process B. Aluminum melt was casting into metal mould at $740^{\circ} \mathrm{C}$, and then cooled to room temperature. The size of the ingots was $20 \mathrm{~mm} \times$ $70 \mathrm{~mm} \times 110 \mathrm{~mm}$.

According to the DSC analysis results and the references $[7,8]$, the ranges of homogenization process parameters were determined as follows: homogenization temperature $400 \sim 600^{\circ} \mathrm{C}$, holding time $6 \sim 18$ hours. The specific process parameters were setting up as follows: (1) homogenization temperature: $400^{\circ} \mathrm{C}, 450^{\circ} \mathrm{C}, 500^{\circ} \mathrm{C}, 550^{\circ} \mathrm{C}, 600^{\circ} \mathrm{C}$; (2) holding time: $6 \mathrm{~h}, 9 \mathrm{~h}, 12 \mathrm{~h}, 15 \mathrm{~h}, 18 \mathrm{~h}$.

The columnar samples were cut directly from the ingots and machined into the cylindrical gauge samples according to GB6397-86. The design chart of the sample is shown in Fig. (1). Room temperature tensile test was carried out by the INSTRON-1185 electronic universal material testing machine. The rate of extension is designed as $3.80 \times 10^{-3} \mathrm{~s}^{-1}$.

The fracture morphologies of tensile samples were observed by using XL30-ESEM, and the semi-quantitative composition analysis of the second phase and the inclusion which were in the metallographic sample or tensile dimple, was carried out by EDAX32 spectrum analyzer.

\section{RESULTS AND ANALYSIS}

\subsection{Mechanical Properties of Al-1Mn-1Mg Alloy Ingot}

The change rules of mechanical properties of $\mathrm{Al}-1 \mathrm{Mn}$ $1 \mathrm{Mg}$ ingots prepared by different processes are shown in Figs. $(\mathbf{2}, \mathbf{3})$.
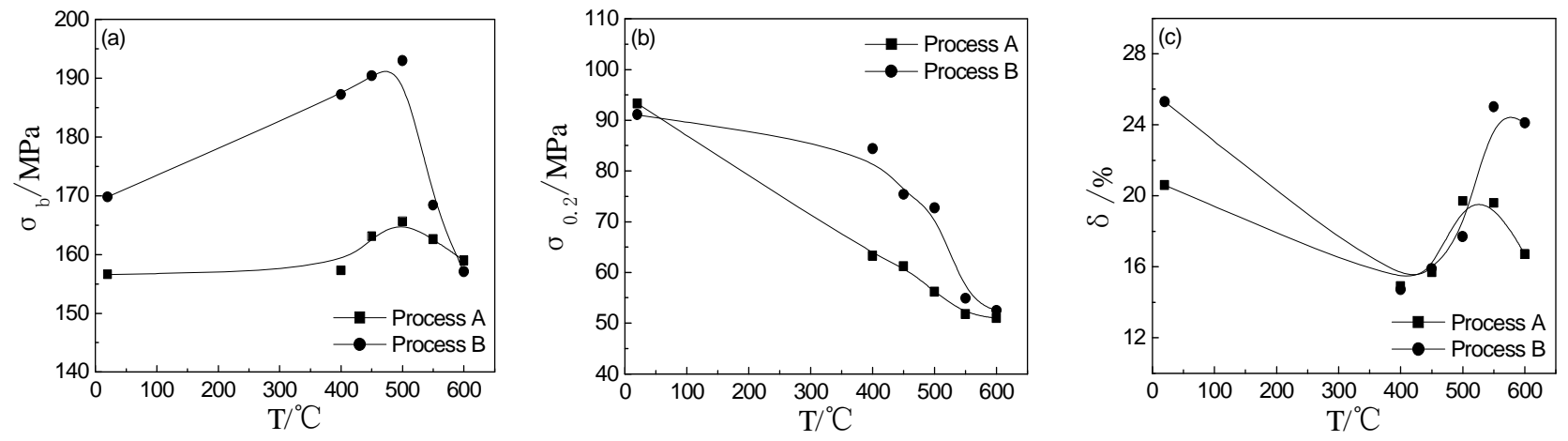

Fig. (2). Curves of mechanical properties of Al-1Mn-1Mg alloy prepared by different melt- treatments and homogenized at different temperature for 12 hours. (a) $\sigma \sim \mathrm{T} ;(\mathbf{b}) \sigma \sim \mathrm{T} ;$; (c) $\delta \sim \mathrm{T}$.
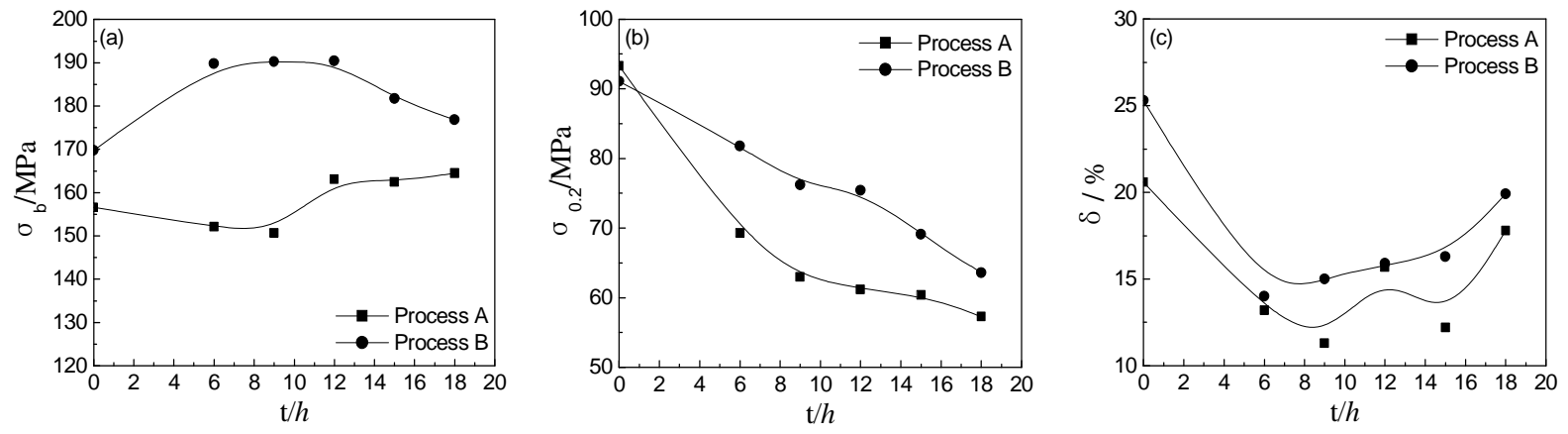

Fig. (3). Curves of mechanical properties of Al-1Mn-1Mg alloy prepared by different melt- treatments and homogenized for different holding time at $450{ }^{\circ} \mathrm{C}$. (a) $\sigma_{\mathrm{b}} \sim \mathrm{T}$; (b) $\sigma_{0.2} \sim \mathrm{T} ;$ (c) $\delta \sim \mathrm{T}$. 
(1) Tensile strength $\left(\sigma_{\mathrm{b}}\right)$ of the ingots prepared by different melt-treatments increase with the rising of homogenization temperature for the same holding time. Peak strength appeared at $500^{\circ} \mathrm{C}$, and then decreased, as shown in Fig. (2a). Compared with the as-cast sample, elongation $(\delta)$ was firstly decreasing significantly with the rising temperature, appearing little change at $400^{\circ} \mathrm{C}$ and $450^{\circ} \mathrm{C}$, rising a little more when the temperature was higher than $450^{\circ} \mathrm{C}$, and beginning to decrease when the temperature was higher than $550^{\circ} \mathrm{C}$, see Fig. (2c). Tensile strength of ingots prepared by process $\mathrm{B}$ was bigger than that of process B significantly at different homogenization temperature. At the same homogenization temperature which was between $400^{\circ} \mathrm{C}$ and $500^{\circ} \mathrm{C}$, the average increase rate of $\sigma_{\mathrm{b}}$ of the ingots prepared by process $\mathrm{B}$ reached $17.4 \%$, and $\delta$ increased by $27.6 \%$ accordingly.

(2) With the holding time extending, tensile strength of the ingots prepared by process $B$ reached the peak value when holding for 12 hours, and altered little after holding for 6 to 12 hours at the certain temperature, and decreased significantly when the holding time was longer than 12 hours. However, the tensile strength of the ingots prepared by process A remained in the strength level of the as-cast samples, as shown in Fig. (3a). With the extension of holding time, Fig. (3c) showed that the alteration trend of the ingots' elongation was similar to that of the temperature. In the same homogenization condition, $\sigma_{\mathrm{b}}$ and $\delta$ of the ingots prepared by process B were obviously better than those of the ingots prepared by process A, and exhibited the better obdurability.

With the homogenization temperature increasing or the holding time extending, the yield strength $\left(\sigma_{0.2}\right)$ of the ingots prepared by different melt-treatments exhibited the same alteration rule, declined gradually and were less than that of as-cast samples. But the $\sigma_{0.2}$ of the ingots prepared by process B was bigger than that of ingots prepared by process A after homogenization, as shown in Figs. (2b, 3b).

The comprehensive mechanical properties of the ingots prepared by different melt-treatments increased to the properties' level of as-cast samples, when the homogenization temperature was higher than $550^{\circ} \mathrm{C}$ or the holding time was longer than $18 \mathrm{~h}$. The result showed that the microstructure under these conditions has been getting worse.

\subsection{Tensile Fracture Morphology of Al-1Mn-1Mg Ingots}

SEM morphologies of tensile fracture of Al-1Mn-1Mg ingots prepared by different processes are shown in Fig. (4).

Through the comparison in Fig. (4), it can be found that: there is no obvious difference of dimples morphology between the as-cast sample prepared by process $\mathrm{A}$ and the homogenized samples, as shown in Fig. $(\mathbf{4 a}, \mathbf{b})$; the size and the distribution state of the dimples in the homogenized samples were not uniform; Fig. (4b) showed that there were bigger shrinkage and gas holes in the fracture, and the visible block precipitated phase and aggregating inclusions can be found in the fractures, as shown in Fig. $(\mathbf{4 c}, \mathbf{d})$; a number of crack sources in the ingots prepared by process B, have been reduced, the dimples in the fractures were deep, tiny, uniform and distributing axially, see Fig. (4e); the fracture morphologies of the homogenized samples were similar to those of the as-cast samples, as shown in Fig. (4e, f); the precipitated particles were tiny, dispersal and can be found in the dimples, see Fig. (4g); the matrix had good continuity and crack resistance; the main fracture mechanism was the type of transgranular and microporous gathering, thus improving the mechanical properties of the ingots; with the homogenization temperature increasing or the holding time extending, the coarse secondary dendrite has been found in the dimples of ingots prepared by process A, and the dimples were still tinier and distributing uniform in the fracture of the ingots prepared by process B, see Fig. (4i).

The precipitated phases and the inclusions in the dimples have been analyzed by EDS, and element semi-quantitative determination results of the phases are listed in Table 2.

The results showed that: the precipitated phases in the fracture dimples of ingots prepared by process $\mathrm{A}$ and homogenization, was the $\mathrm{Al}(\mathrm{Fe}, \mathrm{Mn}, \mathrm{Si})$ phase, and may be adhered by $\mathrm{Al}_{2} \mathrm{O}_{3}$ and $\mathrm{MgO}$ (point $\mathrm{A}$ in Fig. 4c); the big block inclusion in the dimple may be aggregated with $\mathrm{Al}_{4} \mathrm{C}_{3}$, oxide (e.g. $\mathrm{Al}_{2} \mathrm{O}_{3}, \mathrm{MgO}$ ) and a very small amount of alkali chloride (e.g. $\mathrm{NaCl}$ ) (point $\mathrm{B}$ in Fig. 4d); the tiny precipitated phases in the fracture dimples of ingots prepared by process B and homogenization, was mainly the $\mathrm{Al}(\mathrm{Fe}, \mathrm{Mn}, \mathrm{Mg}, \mathrm{RE})$ composite phase with low ratio of $\mathrm{Fe} / \mathrm{Mn}$ (point $\mathrm{C}$ in Fig. 4g).

\subsection{Influence of Metallurgical Defects on the Mechanical Properties of Al-1Mn-1Mg Ingots Homogenized}

Homogenization has been mainly adopted to make atoms distribute uniformly, and cannot eliminate metallurgical defects such as inclusion and gas holes in the original microstructure of the ingots. Because of the poor effect of removing inclusions and degassing in the process $\mathrm{A}$, the continuity of the ingot matrix was destroyed seriously by inclusions and gas already existing in the ingots. Bonding strength inner the matrix was lowered, and the microcracks were easy to initiate in the interface of matrix and inclusions, gas holes or microporosity. Under the action of external forces continuously, the matrix in the crack tip will slip, the tips of microcracks will be blunt to be one cavity quickly, the main crack will continue expanding and link up into a single stretch with microporosity and gas holes [9]. Therefore, plasticity and toughness of the alloy decreased, which led to premature fracture eventually. The crack mechanism was mixed with microporosity and transgranular microporous gathering. In addition, the phases which were bulky fishbone or Chinese characters shape [10] and precipitated in the grain boundary of ingot prepared by process $\mathrm{A}$, can dissolve into the matrix or become round by heated at the higher homogenization temperature or holding for a longer time. Therefore, under the experimental conditions, the mechanical properties, especially the plasticity, of those ingots can be still weakened obviously by the bigger phases precipitating in the grain boundary.

However, the metallurgical quality of the ingots prepared by process $B$ has been improved significantly, i.e. the content of the inclusion or gas in the ingots has been 

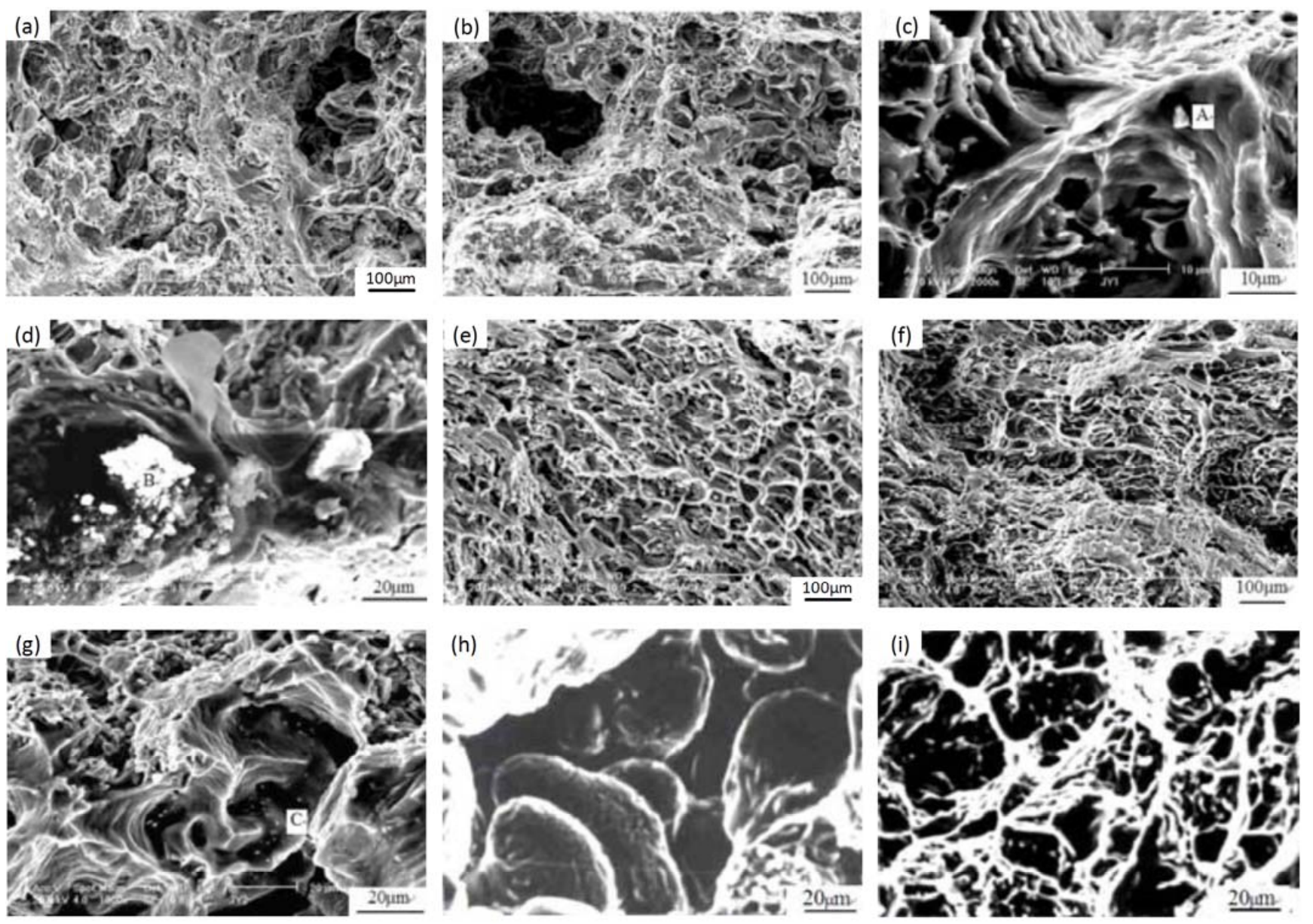

Fig. (4). SEM morphologies of tensile fracture of Al-1Mn-1Mg ingots prepared by different processes (a) process A, as-cast; (b) process A, $450^{\circ} \mathrm{C} \times 12 \mathrm{~h}$; (c) process $\mathrm{A}, 450^{\circ} \mathrm{C} \times 12 \mathrm{~h}$; (d) process $\mathrm{A}, 450^{\circ} \mathrm{C} \times 12 \mathrm{~h} ;(\mathbf{e})$ process $\mathrm{B}$, as-cast; (f) process $\mathrm{B}, 450^{\circ} \mathrm{C} \times 12 \mathrm{~h}$; $(\mathbf{g})$ process $\mathrm{B}$, $450^{\circ} \mathrm{C} \times 12 \mathrm{~h}$; (h) process $\mathrm{A}, 550^{\circ} \mathrm{C} \times 12 \mathrm{~h}$; (i) process B, $550^{\circ} \mathrm{C} \times 12 \mathrm{~h}$.

Table 2. Semi Quantitative Element Determination Data of Impurities in the Tensile Fracture Dimples of the Ingots Homogenized

\begin{tabular}{|c|c|c|c|c|c|c|c|c|c|c|c|c|}
\hline Detected Point & \multicolumn{12}{|c|}{ Element Composition (wt\%) } \\
\hline B & 43.57 & 23.16 & 1.41 & 0.56 & 4.54 & & & 0.31 & 0.24 & 0.56 & 0.60 & \multirow[t]{2}{*}{ Bal. } \\
\hline $\mathrm{C}$ & & & & & 1.64 & 2.42 & 3.31 & & & 13.99 & 7.01 & \\
\hline
\end{tabular}

lowered, the grains are tiny and distributed uniformly, the precipitated phases have been become tiny and round, the segregation of microstructure and composition has been reduced. And the ideal state of the homogeneous microstructure can be obtained easily by homogenization at the lower temperature or for the shorter holding time. Under the same homogenization conditions, the elongation of the ingots prepared by process B can still maintain higher, when the strength of the ingots prepared by process B increased more greatly than that of the ingots prepared by process A. The better homogenization process parameters were obtained as follows: homogenized at $450 \sim 500^{\circ} \mathrm{C}$, held for 12 hours, air-cooling. And then, the better comprehensive mechanical properties were as follows: $\sigma_{\mathrm{b}} \approx 180.0 \sim 193 \mathrm{MPa}, \delta \approx 16.0 \sim 18.0 \%$.

\section{CONCLUSIONS}

(1) Metallurgical defects such as inclusions, gas holes and so on, which were in the original microstructure of the ingots, cannot be eliminated by homogenization, so there was little effect on the mechanical properties and fracture mode of the ingots prepared by the conventional melt-treatment.

(2) The strength of the ingots prepared by the comprehensive melt-treatment was higher than that of the ingots prepared by the conventional melt-treatment; and the average increase rate of the tensile strength of ingots prepared by conventional process reached $17.4 \%$, and the elongation increased slightly, then the better obdurability can be 
obtained with the major fracture mode of transgranular microporous gathering.

(3) The comprehensive mechanical properties of the ingots prepared by different melt-treatments increased to the properties' level of as-cast samples, when the homogenization temperature is higher than $550^{\circ} \mathrm{C}$ or the holding time was longer than $18 \mathrm{~h}$.

(4) Under the test conditions, the optimized homogenization process parameters of $\mathrm{Al}-1 \mathrm{Mn}-1 \mathrm{Mg}$ alloy prepared by the comprehensive melt-treatment are as follows: $450 \sim 500^{\circ} \mathrm{C}$, holding for 12 hours and air cooling; The better comprehensive mechanical properties can be obtained, which were, $\sigma_{\mathrm{b}} \approx 180.0 \sim 193 \mathrm{MPa}, \delta \approx 16.0 \sim 18.0 \%$.

\section{CONFLICT OF INTEREST}

The authors confirm that this article content has no conflict of interest.

\section{ACKNOWLEDGEMENTS}

This work was financially supported by Scientific Research Foundation for Talents Introduction of Fujian University of Technology (GY-Z0627), Science and Technology Program of the Educational Committee of
Fujian Province (JA09173), Key Program of Committee of Science and Technology of Fujian Province (2010H0002).

\section{REFERENCES}

[1] Liu JT, Banovic SW, Fields RJ, Morris JG. Effect of intermediate heat treatment on microstructure and texture evolution of continuous cast Al-Mn-Mg alloy sheet. Metall Mater Trans A 2006; 37: 1887-98.

[2] Birol Y. Recrystallization of a supersaturated Al-Mn alloy Scr Mater 2008; 59: 611-4.

[3] Engdahl T, Hansen V, Warren PJ, Stiller K. Investigation of fine scale precipitates in $\mathrm{Al}-\mathrm{Zn}-\mathrm{Mg}$ alloys after various heat treatments. Mater Sci Eng A 2002; A327: 59-64.

[4] Aghaie-Khafri M, Mahmudi R. Optimizing homogenization parameters for better stretch formability in an $\mathrm{Al}-\mathrm{Mn}-\mathrm{Mg}$ alloy sheet. Mat Sci Eng A-Struct 2005; 399: 173-80.

[5] Chen YL, Fu GS, Chen WZ. J Fujian Technol Univ 2003; 1: 11.

[6] Fu GS, Kang JX, Chen WZ, Qian KW. Chin J Nonferrous Met 2001; 11: 433-6

[7] Saimoto S, Kamat RG. Mater Sci Technol 1992; 8: 869-74.

[8] Sun DL, Kang SB, Koo HS. Characteristics of morphology and crystal structure of $\alpha$-phase in two Al-Mn-Mg alloys. Mater Chem Phys 2000; 63: 37-43.

[9] Saxena A, Shukla SK, Chaudhuri SK. Microstructure and texture formation in high strength cold rolled and annealed sheet and their correlation with formability property. J Mat Eng Perform 2003; 12: 317.

[10] Chen YL, Fu GS, Chen WZ. Influence of homogenization on morphologies of the precipitated phases in A-1 $1 \mathrm{Mn}-1 \mathrm{Mg}$ alloy. Trans Mater Heat Treat 2006; 27: 40-4. 